\title{
Angle Recession in Patients with Closed Globe Injury
}

\author{
Mohammad Farhan ${ }^{1}$, Omar Illyas ${ }^{2}$, Mubashir Rehman ${ }^{3}$, Jawad Humayun ${ }^{4}$, Adnan Ahmad ${ }^{5}$ \\ ${ }^{1,3,4,5}$ Nowshera Medical College, Nowshera, ${ }^{2}$ Gajju Khan Medical College, Swabi
}

\begin{abstract}
Purpose: To determine the frequency of angle recession following closed globe injury in patients presenting to the department of ophthalmology of a tertiary care hospital of Pakistan.
\end{abstract}

Study Design: Descriptive observational study.

Place and Duration of Study: Study was conducted at Eye-A Unit, Hayatabad Medical Complex, Peshawar from $14^{\text {th }}$ March 2017 to $14^{\text {th }}$ Sept 2017.

Methods: One hundred and sixty three patients were selected for this study after applying WHO sample size calculation formula. Patients with history of closed globe injury were recruited through consecutive sampling technique. A detailed history regarding trauma, causative agent, duration of injury and site of impact was taken. Ocular examination including visual acuity and detailed examination of both anterior and posterior segment was carried out using slit lamp biomicroscope. Gonioscopy was performed to check the presence and extent of angle recession.

Results: Mean age was $33 \pm 8.82$ years. Seventy five percent patients were male and $25 \%$ female. Type of trauma included; 57 (35\%) patients had road traffic accidents, $33(20 \%)$ patients had stone injuries, $37(23 \%)$ patients had sports injuries while $36(22 \%)$ patients had eye trauma due to other types like fall, fight, glass injuries, chemical exposures etc. In 90 (55\%) patients, right eye was affected while 73 (45\%) patients had trauma in left eye. Duration of trauma was $\leq 2$ days in $124(76 \%)$ patients while mean duration was 1 day with SD \pm 1.034 .

Conclusion: Frequency of angle recession was $28 \%$ following closed globe injury.

Key Words: Angle recession, closed globe injury, ocular trauma.

How to Cite this Article: Farhan M, Illyas O, Rehman M, Humayun J, Ahmad A. Angle Recession in Patients with Closed Globe Injury. Pak J Ophthalmol. 2022, 38 (1): 58-62.

Doi: $10.36351 /$ pjo.v38i1.1248

Correspondence: Mubashir Rehman

Department of Ophthalmology

Nowshera Medical College

Nowshera

Email:drmubashirrehman78@gmail.com

Received: March 31, 2021

Revised: July 28, 2021

Accepted: December 12, 2021

\section{INTRODUCTION}

Ocular trauma is one of the important causes of preventable blindness globally. ${ }^{1}$ Eighteen million people worldwide have uniocular blindness from traumatic injury. ${ }^{2}$ In the United States, there are approximately 2.5 million cases of eye trauma every year, resulting in approximately 50000 people who suffer from partial or complete loss of vision. In addition, the rates at which eye injuries require hospitalization are in the range of 4.9-89 per 10 million in developing countries. ${ }^{3}$ 
Blunt trauma forms a major part of ocular trauma. Squash balls, elastic luggage straps, falls and champagne corks are the most common causes of blunt ocular trauma. ${ }^{4}$ Blunt ocular trauma or ocular contusions cause an antero-posterior compression of the globe and elongation of the equatorial area. Both anterior and posterior segment structures may be influenced by this rapid deformation of ocular tissues. Cornea, iris, lens and zonules are the most affected tissues from trauma as they are vulnerable to acute deformation. ${ }^{5}$ Hyphema, glaucoma, angle recession, iris deformities, cataract, and lens luxation or subluxation are reported complications of ocular contusion. $^{6}$

Angle recession is a common result of blunt trauma. As contact with the globe occurs, anterior-toposterior compression forces the aqueous laterally, stressing the limbus. The longitudinal fibers of the ciliary muscle become separated from the circular fibers. This can also shear small vessels of the anterior ciliary arteries, leading to hyphema. ${ }^{7}$

The incidence of angle recession after eye trauma ranges from 20 to $94 \% .{ }^{8}$ Patients with traumatic angle recession are prone to develop angle recession glaucoma. The possibility of developing glaucoma in an eye with angle recession appears to be related to the extent of angle recession. If more than $180^{\circ}$ of the anterior chamber angle is involved, there is a greater chance of subsequent development of glaucoma. ${ }^{8}$

Anterior chamber angle recession has been reported to be the most common sign of previous blunt trauma to the eye.

A patient who has experienced blunt ocular trauma needs a comprehensive eye examination for the presence of angle recession and other abnormalities. ${ }^{9}$ As angle-recession glaucoma can occur even many years after trauma, patients should receive adequate counselling, and follow-up examinations should be performed regularly.

This study will give us a magnitude of angle recession following closed globe injury in our setup, which can help in early diagnosis of angle recession glaucoma in future.

\section{METHODS}

The total sample size was 163 by using WHO sample size calculator, based on $14.6 \%$ prevalence of angle recession after blunt ocular trauma where confidence level $=95$, absolute precision $=5 \%$ and population proportion $(\mathrm{P})=14.6 \%$. Consecutive (non-probability) sampling technique was used for sample selection. All patients presenting with closed globe injury (diagnosed on clinical examination), with duration of less than 01 week and intensity mild to severe were selected. Age ranged from 18 to 60 years. Patients of either gender were included in the study. Noncooperative patients, patients not willing to be part of the study and those having corneal opacity obscuring angle view (on the basis of clinical examination) were excluded from the study. Closed globe injury was defined as trauma to eyeball in which the corneoscleral wall of the globe was intact. Closed globe injuries were further classified on the basis of visual acuity on initial examination as mild when initial visual acuity was equal to or greater than $6 / 12$, moderate when initial visual acuity was greater than $3 / 60$ but less than $6 / 12$ and severe when the initial visual acuity was less than $3 / 60$. Angle recession was considered as variable degree of cleavage between circular and longitudinal fibres of the ciliary muscle seen on gonioscopy. The purpose and benefits of the study was explained to the patients/attendants and written informed consent was obtained from each patient. A data collection proforma was filled for each patient having a detailed record of the disease including age, gender and laterality. A detailed history regarding trauma, causative agent, duration of injury and site of impact was noted. Ocular examination including visual acuity and detailed examination of both anterior and posterior segment was carried out using slit lamp. Gonioscopy was performed to check the presence and extent of angle recession. All the analysis was done in SPSS version 20.0. Frequencies and percentages were calculated for categorical variables like gender, type of trauma, laterality and angle recession. Mean \pm Standard Deviation was computed for numeric variable like age and duration of trauma. Angle recession was stratified among age, gender, laterality, type of trauma and duration of trauma to see effect modifications. Post stratification Chi Square test was applied keeping P-value $<0.05$ as significant. All the results were presented in the form of tables and charts.

\section{RESULTS}

In this study, mean age was $33 \pm 8.821$ years. Sixty five $(40 \%)$ patients were $20-30$ years of age, 54 (33\%) 
patients were in the age range of $31-40$ years, 33 (20\%) patients were between $41-50$ years and 11 (7\%) patients were $51-60$ years. There were 122 (75\%) males and $41(25 \%)$ females. Ninety (55\%) patients had trauma in right eye while 73 (45\%) patients had trauma in left eye. Duration of trauma was $\leq 2$ days in $124(76 \%)$ patients and $39(24 \%)$ patients had duration of trauma of $>2$ days. Mean duration was 1 day with $\mathrm{SD} \pm 1.034$. Road traffic accident was the cause of trauma in 57 (35\%) patients, 33 (20\%) patients had stone injuries, 37 (23\%) patients had sports injuries while $36(22 \%)$ patients had eye trauma due to other causes; e.g. fall, fight, glass injuries, chemical exposures etc. Forty six (28\%) patients had angle recession while 117 (72\%) patients did not have angle recession. Stratification of angle recession with age, type of trauma and duration of trauma is given in tables 1,2 and 3.

Table 1: Stratification of Angle Recession with Respect to Age Distribution $(N=163)$.

\begin{tabular}{|c|c|c|c|c|c|}
\hline $\begin{array}{l}\text { Angle } \\
\text { Recession }\end{array}$ & $\begin{array}{c}20-30 \\
\text { Years } \\
\end{array}$ & $\begin{array}{c}31-40 \\
\text { years }\end{array}$ & $\begin{array}{c}41-50 \\
\text { Years } \\
\end{array}$ & $\begin{array}{c}51-60 \\
\text { Years } \\
\end{array}$ & Total \\
\hline Yes & 18 & 15 & 9 & 4 & 46 \\
\hline No & 47 & 39 & 24 & 7 & 117 \\
\hline Total & 65 & 54 & 33 & 11 & 163 \\
\hline
\end{tabular}

Chi Square test was applied in which P value was 0.9425

Table 2: Stratification of Angle Recession with Respect to Duration of Trauma $(N=163)$.

\begin{tabular}{lccc}
\hline Angle Recession & < 2 Days & > 2 Days & Total \\
\hline Yes & 35 & 11 & 46 \\
No & 89 & 28 & 117 \\
Total & $\mathbf{1 2 4}$ & $\mathbf{3 9}$ & $\mathbf{1 6 3}$ \\
\hline
\end{tabular}

Chi Square test was applied in which P value was 0.9980

Table 3: Stratification of Angle Recession with Respect to Type of Trauma $(N=163)$.

\begin{tabular}{lccccc}
\hline $\begin{array}{l}\text { Angle } \\
\text { Recession }\end{array}$ & $\begin{array}{c}\text { RTA } \\
\text { Injuries }\end{array}$ & $\begin{array}{c}\text { Stone } \\
\text { Injuries }\end{array}$ & $\begin{array}{c}\text { Sports } \\
\text { Injuries }\end{array}$ & $\begin{array}{c}\text { Other } \\
\text { Injuries }\end{array}$ & Total \\
\hline Yes & 16 & 9 & 11 & 10 & 46 \\
No & 41 & 24 & 26 & 26 & 117 \\
Total & $\mathbf{5 7}$ & $\mathbf{3 3}$ & $\mathbf{3 7}$ & $\mathbf{3 6}$ & $\mathbf{1 6 3}$ \\
\hline
\end{tabular}

Chi Square test was applied in which $\mathrm{P}$ value was 0.9961

\section{DISCUSSION}

Our study shows that the mean age was 33 years with $\mathrm{SD} \pm 8.821$. The frequency of angle recession was found to be $28 \%$ following closed globe injury. In a study done in central India, it was seen that out of a total of 220 cases of trauma, mean age was $8.74 \pm 3.93$ years, males were predominantly affected and open globe injuries outnumbered blunt injuries. ${ }^{10}$ Another researcher reported Cricket-related ocular injuries. His results showed that these injuries had poor prognosis with most cases being closed globe injuries with retinal detachment. Angle recession was seen in $18 \%$ cases in his series. ${ }^{11}$ It has been reported that among patients who experience traumatic angle recession, 5\% to $20 \%$ will develop glaucomatous optic neuropathy. ${ }^{12}$ Literature shows that no difference was seen between the incidences of angle-recession glaucoma when comparing hyphema versus microhyphema. ${ }^{13}$ A study conducted by Kaur $\mathrm{S}$, et al ${ }^{14}$ showed that the incidence of angle recession after eye trauma ranged from 20 to $94 \%$.

According to one study, a total of 5 to $20 \%$ of patients with traumatic angle recession would go on to develop glaucoma. ${ }^{15}$ A very low incidence of only 7$9 \%$ is reported by other author, which is quite less than our results. ${ }^{16}$

The possibility of developing glaucoma in an eye with angle recession appears to be related to the extent of angle recession. ${ }^{17}$ On examination, if there is presence of increased pigmentation at the angle, raised IOP, blood in anterior chamber, subluxation of lens, and angle recession of more than 180 degrees, there are chances that it will lead to chronic glaucoma after closed globe injury. UBM findings include a wider angle and the absence of cyclodialysis cleft. ${ }^{18}$ If more than $180^{\circ}$ of the anterior chamber angle is involved, there is a greater chance of subsequently developing glaucoma. ${ }^{19}$

Similar findings were observed in another study conducted by Salmon JF et $\mathrm{al}^{20}$ in which anterior chamber angle recession had been reported to be the most common sign of previous blunt trauma to the eye. The prevalence of post-traumatic angle recession in that report was $14.6 \%$.

Limitation of the study is that it lacks long term follow up which is a mandatory part of examination of a patient with blunt ocular trauma. Further longitudinal studies are required for this purpose.

\section{CONCLUSION}

Our study concludes that the frequency of angle recession was $28 \%$ following closed globe injury. 
Patients with blunt trauma need long term follow up which should include Gonioscopy as a mandatory part of examination.

\section{Ethical Approval}

The study was approved by the Institutional review board/Ethical review board (227/HEC/B\&PSC/2016).

\section{Conflict of Interest}

Authors declared no conflict of interest.

\section{REFRENCES}

1. Osman EA, Al-Fawaz N, Al-Otaibi AG, AlMansouri SM, Mousa A, Al-Mezaine HS. Glaucoma after open globe injury at a tertiary care university hospital in Central Saudi Arabia. Saudi Med J 2012; 33 (4): 374-378.

2. Abbott J, Shah P. The epidemiology and etiology of pediatric ocular trauma. Surv Ophthalmol. 2013; 58 (5): 476-485.

3. Qi Y, Zhang FY, Peng GH, Zhu Y, Wan GM, Wang WZ, et al. Characteristics and visual outcomes of patients hospitalized for ocular trauma in central China: 2006-2011. Int J Ophthalmol. 2015; 8 (1): 162-168.

4. Pai SG, Kamath SJ, D'Souza S, Dudeja L. A Clinical Study of Blunt Ocular Trauma in a Tertiary Care Centre. Online J Health Allied Scs. 2013; 12 (2): 10.

5. Firat PG, Doganay S, Cumurcu T, Demirel S, Kutukde D. Anterior Segment Complications in Ocular Contusion. J Trauma Treatment, 2011; 1: 101.

6. Puodžiuvienė E, Jokūbauskienė $\mathbf{G}$, Vieversytė $M$, Asselineau K. A five-year retrospective study of the epidemiological characteristics and visual outcomes of pediatric ocular trauma. BMC Ophthalmol. 2018; 18: 10.

7. Paciuc M, Dalma-Weiszhausz J, Phan R, Smits D, Velez-Montoya R. Trauma: Anterior segment injuries. American Academy of Ophthalmology. Nov. 2015.

8. Kaur S, Kaushik S, Pandav SS. Traumatic Glaucoma in Children. J Curr Glaucoma Pract. 2014; 8 (2): 58-62.

9. Herschler J. Trabecular damage due to blunt anterior segment injury and its relationship to traumatic glaucoma. Trans Sect Ophthalmol Am Acad Ophthalmol Otolaryngol. 1977; 83 (2): 239-248. PMID: 406709.

10. Singh S, Sharma B, Kumar K, Dubey A, Ahirwar K. Epidemiology, clinical profile and factors, predicting final visual outcome of pediatric ocular trauma in a tertiary eye care center of Central India. Indian J Ophthalmol. 2017; 65: 1192-1197.

11. Mahapatra SK, Malhotra K, Mendke RG. A 3-year prospective study on ocular injuries with tennis or cricket ball while playing cricket: A case series. Indian J Ophthalmol. 2018; 66: 256-261.
12. Nguyen QH. Clinical Approach to Angle-recession Glaucoma. Early diagnosis and the aggressive management of elevated IOP after blunt trauma are essential. Glaucoma Today, 2012: 37-38.

13. Ng DS, Ching RH, Chan CW. Angle-recession glaucoma: long-term clinical outcomes over a 10-year period in traumatic microhyphema. Int Ophthalmol. 2015; 35 (1): 107-13. Doi: 10.1007/s10792-014-00275. Epub 2014 Dec 18. PMID: 25520267.

14. Kaur S, Kaushik S, Pandav SS. Traumatic Glaucoma in Children. J Curr Glaucoma Pract. 2014; 8 (2): 58-62.

15. Kalamkar $\mathbf{C}$, Mukherjee A. Incidence, clinical profile, and short-term outcomes of post-traumatic glaucoma in pediatric eyes. Indian J Ophthalmol. 2019; 67 (4): 509-514.

16. Razeghinejad R, Lin MM, Lee D, Katz LJ, Myers JS. Pathophysiology and management of glaucoma and ocular hypertension related to trauma. Surv Ophthalmol. 2020; 65 (5): 530-547.

17. Mokbel TH, El Hefney EM, Hagras SM, AL Nagdy AA, Badawi AE, Kasem MA, et al. Childhood glaucoma profile in Dakahelia, Egypt: a retrospective study. Int J Ophthalmol. 2018; 11 (4): 674-680.

18. Sihota R, Kumar S, Gupta V, Dada T, Kashyap S, Insan R, et al. Early predictors of traumatic glaucoma after closed globe injury: trabecular pigmentation, widened angle recess, and higher baseline intraocular pressure. Arch Ophthalmol. 2008; 126 (7): 921-926. Doi: 10.1001/archopht.126.7.921. PMID: 18625937.

19. Mansoori T, Reddy AA, Balakrishna N. Identification and Quantitative Assessment of Schlemm's Canal in the Eyes with $360^{\circ}$ Angle Recession Glaucoma. J Curr Glaucoma Pract. 2020; 14 (1): 25-29.

20. Salmon JF, Mermoud A, Ivey A, Swanevelder SA, Hoffman M. The detection of post-traumatic angle recession by gonioscopy in a population-based glaucoma survey. Ophthalmology, 1994; 101 (11): 1844-1850.

\section{Author's Designation and Contribution}

Mohammad Farhan; Senior Registrar: Concepts, Design, Data Acquisition, Data Analysis, Statistical Analysis, Manuscript Preparation, Manuscript Editing, Manuscript Review.

Omar Ilyas; Medical Officer: Concepts, Design, Data Acquisition, Data Analysis, Statistical Analysis, Manuscript Preparation, Manuscript Editing, Manuscript Review.

Mubashir Rehman; Associate Professor: Concepts, Design, Data Acquisition, Data Analysis, Statistical Analysis, Manuscript Preparation, Manuscript Editing, Manuscript Review. 
Jawad Humayun; Junior Registrar: Literature Search, Manuscript Review.
Adnan Ahmad; Assistant Professor: Literature Search, Manuscript Review.

\section{$\cdots \cdot \mathbf{c} \cdot \cdots$}

